\title{
Prevalence of multidrug resistance (MDR) and extended spectrum beta- lactamases (ESBLs) among uropathogenic Escherichia coli isolates from female patients in a tertiary care hospital in North India
}

\author{
Bhaskar Das $^{1 *}$, Natasha Mittal ${ }^{2}$, Rajni Goswami ${ }^{1}$, Deepti Adhana ${ }^{1}$, Neha Rathore ${ }^{1}$
} ${ }^{1}$ Department of Microbiology, ${ }^{2}$ Department of Pathology, Sarvodaya Hospital and Research Centre, Faridabad,
Haryana, India

Received: 01 October 2018

Accepted: 27 October 2018

\author{
*Correspondence: \\ Dr. Bhaskar Das, \\ E-mail: drbhaskarinnet@gmail.com
}

Copyright: $($ ) the author(s), publisher and licensee Medip Academy. This is an open-access article distributed under the terms of the Creative Commons Attribution Non-Commercial License, which permits unrestricted non-commercial use, distribution, and reproduction in any medium, provided the original work is properly cited.

\begin{abstract}
Background: Urinary tract infection (UTI) is a common bacterial infection in women. It is very common during pregnancy and may present as asymptomatic bacteriuria. Escherichia coli is the primary urinary pathogen accounting for $74-90 \%$ of uncomplicated urinary tract infection. The aim of the study was to evaluate in-vitro antibiotic susceptibility among urine isolates of Escherichia coli and prevalence of resistance marker like ESBL producer and MDR status.

Methods: Mid-stream urine samples of 205 female patients were processed for culture and sensitivity. All the samples were inoculated on culture media and growth showing significant bacteriuria $\left(>10^{5} \mathrm{cfu} / \mathrm{ml}\right)$ were subjected to identification and antibiotic sensitivity testing on Automated system BD Phoenix 100. ESBL status was detected by the system and MDR status was evaluated by standard guidelines.

Results: Out of 205 urine samples, 47 samples (22.93\%) showed growth of organism. Out of the 47 growth positive samples, 36 (76.60\%) samples showed growth of Escherichia coli and out of which $13(36.11 \%)$ were ESBL producer and $23(63.89 \%)$ were ESBL non-producer. Escherichia coli was mostly isolated from younger age group (21-40 years) $(61.11 \%)$. Antimicrobial susceptibility showed very good sensitivity towards Amikacin, Tigecycline, Carbapenems, Fosfomycin, Piperacillin-tazobactam and Nitrofurantoin. All the isolates of ESBL producer are MDR $(100 \%)$ and $21.7 \%$ of ESBL non-producer are MDR. There is evidence of transfer of resistance genes for non- $\beta$ lactam antibiotics along with ESBL resistance marker.

Conclusions: Escherichia coli was the predominant uropathogen isolated from female patients and Amikacin, Nitrofurantoin and Fosfomycin can be used as first line drug.
\end{abstract}

Keywords: Asymptomatic bacteriuria, Extended spectrum beta-lactamase, Multidrug resistance, Urinary tract infection, Uropathogen

\section{INTRODUCTION}

Urinary tract infection (UTI) is one of the most common bacterial infection in women and responsible for significant morbidity and health care costs. It is a common problem in pregnancy due to morphological and physiological changes that takes place in genito-urinary tract during pregnancy. Asymptomatic bacteriuria (ASB) is the presence of actively multiplying bacteriuria of more than $10^{5} / \mathrm{ml}$ of urine without any symptom. Escherichia coli is the primary urinary tract pathogen accounting for 74 to $90 \%$ of uncomplicated urinary tract infection. Other bacteria include Staphylococcus saprophyticus, Klebsiella spp, Proteus spp, Enterococcus spp and 
Enterobacter spp..$^{1-3}$ About $50 \%$ of all females experience at least one episode of UTI during their life time. Asymptomatic bacteriuria and urinary tract infections (UTI) have a higher prevalence during pregnancy and in very sexually active females. UTI is an infection that affects any part of the urinary tract from bladder to the kidney. Symptoms include frequent and/or painful urination, urgency, fever and flank pain. The urine may contain pus or blood. UTI is a risk factor for pyelonephritis, preterm delivery and miscarriage among pregnant women. ${ }^{4,5}$

Extended spectrum $\beta$-lactamases (ESBLs) are defined as $\beta$-lactamases capable of hydrolyzing oxyiminocephalosporins and are inhibited by $\beta$-lactamase inhibitors. The primary organism causing urinary tract infection (UTI) like Escherichia coli produce ESBLs. These enzymes are plasmid borne and confer multiple drug resistance, making urinary tract infections difficult to treat. Inappropriate and wide spread use of antibiotics has lead to emergence of resistance markers like production of Extended spectrum $\beta$-lactamases (ESBLs) and concomitant multidrug resistance (MDR). ${ }^{6,7}$

The aim of this study was to determine in-vitro antibiotic susceptibility among urine isolates of Escherichia coli and prevalence of resistance markers like ESBL production and MDR status in female patients to guide the clinicians in patient care.

\section{METHODS}

This is a retrospective study conducted in Department of Microbiology, Sarvodaya Hospital and Research Centre, Sector-8, Faridabad, Haryana, India. Urine samples of female patients received from Obstetrics and Gynecology dept for bacteriological culture and sensitivity testing from September'17 to February'18 were analyzed.

A total of 205 mid-stream urine samples collected in wide mouthed sterile container for aerobic culture and sensitivity were analyzed. Samples were processed within one hour of collection. For routine examination of urine (wet film preparation), $50 \mu \mathrm{l}$ of well mixed uncentrifuged urine was taken on a slide with coverslip placed on it and viewed under high power objective of microscope. The presence of one pus cell per 7 high power field was considered as significant pyuria. For urine culture, $1 \mu 1$ of urine sample was inoculated on HiCrome UTI agar media and MacConkey agar media (HiMedia, Mumbai, India) using a standard loop of internal diameter $1.34 \mathrm{~mm}$ (semiquantitative method). The plates were read after 24 hours of aerobic incubation at 370C. They were further incubated for another 24 hours before reported as negative. ${ }^{8}$ A single organism of colony count $>1,00,000$ $\mathrm{cfu} / \mathrm{ml}$ was subjected to identification and antibiotic sensitivity testing by Automated system BD Phoenix 100 (Becton Dickinson). The Extended Spectrum $\beta$ Lactamase production is also detected by this automated system. Multidrug resistance (MDR) is defined as antibiotic resistance to one or more agent in each of three or more groups of antibiotics. ${ }^{7}$ MDR status was evaluated by calculating the resistance to each drug group. Escherichia coli ATCC 25922, Pseudomonas aeruginosa ATCC 27853 and Staphylococcus aureus ATCC 29213 used as quality control.

\section{RESULTS}

A total of 205 urine samples received in Microbiology Lab from Obstetrics and Gynecology dept. for aerobic culture and sensitivity, out of which 47 (22.93\%) samples yielded positive growth, whereas 158 (77.07\%) samples yielded no growth (Figure 1).

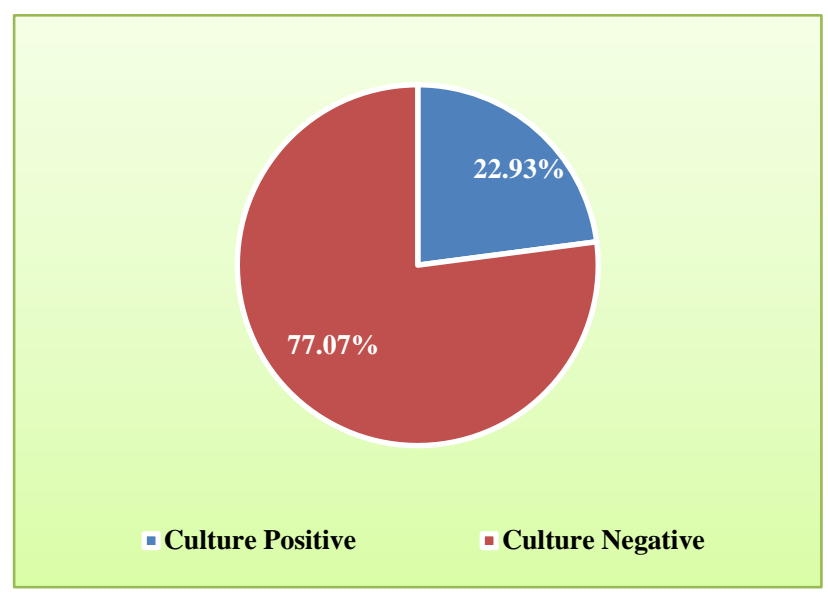

Figure 1: Culture positivity of urine samples in female patients.

Among the 47 positive isolates the predominant gramnegative bacteria was Escherichia coli $(76.60 \%)$ out of which $36.11 \%$ was ESBL producer and $63.89 \%$ was ESBL non-producer. This was followed by Klebsiella pneumoniae (4.25\%), Pseudomonas aeruginosa and Proteus mirabilis (2.13\% each). The predominant grampositive organism was Enterococcus faecalis (6.38\%) followed by Staphylococcus saprophyticus and Staphylococcus haemolyticus $(2.13 \%$ each). The percentage of Candida spp. was $4.25 \%$ (Table 1 ).

Table 1: Distribution of organism isolates obtained from urine samples.

\begin{tabular}{|l|l|}
\hline Organism & Number $(\%)(\mathrm{n}=47)$ \\
\hline Escherichia coli & $36(76.60 \%)$ \\
\hline ESBL producer E. coli & $13(36.11 \%)$ \\
\hline ESBL non-producer E. coli & $23(63.89 \%)$ \\
\hline Klebsiella pneumoniae & $2(4.25 \%)$ \\
\hline Pseudomonas aeruginosa & $1(2.13 \%)$ \\
\hline Proteus mirabilis & $1(2.13 \%)$ \\
\hline Enterococcus faecalis & $3(6.38 \%)$ \\
\hline Staphylococcus saprophyticus & $1(2.13 \%)$ \\
\hline Staphylococcus haemolyticus & $1(2.13 \%)$ \\
\hline Candida spp. & $2(4.25 \%)$ \\
\hline
\end{tabular}


The age group wise distribution of Escherichia coli isolates showed that highest percentage of isolates were from $21-40$ years of age group $(61.11 \%)$ followed by 41 60 years $(22.22 \%)$, whereas ESBL producer Escherichia coli was highest from 41-60 years of age group (38.46\%) followed by $21-40$ years $(30.77 \%)$ (Table 2$)$.

Table 2: Age group wise distribution of Escherichia coli isolates along with ESBL status.

\begin{tabular}{|lll|}
\hline $\begin{array}{l}\text { Age group } \\
\text { distribution }\end{array}$ & $\begin{array}{l}\text { Total E. coli isolates } \\
\text { No }(\%)(n=36)\end{array}$ & $\begin{array}{l}\text { ESBL producer } \\
\text { E. coli No }(\%) \\
(\mathbf{n}=13)\end{array}$ \\
\hline 0 - 20 years & $2(5.56 \%)$ & $1(7.69 \%)$ \\
\hline $21-40$ years & $22(61.11 \%)$ & $4(30.77 \%)$ \\
\hline $41-60$ years & $8(22.22 \%)$ & $5(38.46 \%)$ \\
\hline $61-80$ years & $4(11.11 \%)$ & $3(23.08 \%)$ \\
\hline
\end{tabular}

The overall antimicrobial susceptibility pattern of Escherichia coli showed that the sensitivity was highest in Amikacin and Tigecycline (100\%) followed by
Meropenem and Fosfomycin (97.2\% each), Imipenem (94.4\%), Ertapenem (91.6\%), Piperacillin-tazobactam $(88.9 \%)$, Nitrofurantoin $(86.1 \%)$, Gentamicin $(80.5 \%)$, Tobramycin (72.2\%), Norfloxacin (58.3\%), Ciprofloxacin and Cefepime (52.8\% each), Cefazolin, Ceftazidime, Ceftriaxone, Aztreonam and Trimethoprimsulfamethoxazole (50\% each), Amoxycillin-clavulinic acid (47.2\%) and lastly Ampicillin (27.8\%). The distribution of antimicrobial susceptibility pattern in ESBL producer and ESBL non-producer shows that most of the antibiotic gain resistance along with ESBL resistance marker except Amikacin and Tigecycline where the sensitivity remains the same $(100 \%)$. In case of carbapenems (Meropenem, Imipenem and Ertapenem) and Piperacillin-tazobactam, the sensitivity increases in ESBL producers. The antimicrobial susceptibility pattern in case of most of non- $\beta$-lactam antibiotics like Norfloxacin, Trimethoprim-sulfamethoxazole, Gentamicin, Fosfomycin, Nitrofurantoin shows that the sensitivity decreases in ESBL producers (Table 3).

Table 3: The antimicrobial susceptibility pattern of Escherichia coli.

\begin{tabular}{|llll|}
\hline Antibiotics & $\begin{array}{c}\text { Total sensitivity } \\
\text { No. }(\%)(\mathbf{n}=36)\end{array}$ & $\begin{array}{l}\text { Sensitivity in ESBL } \\
\text { producer No. (\%) (n=13) }\end{array}$ & $\begin{array}{l}\text { Sensitivity in ESBL non- } \\
\text { producer No. (\%) (n=23) }\end{array}$ \\
\hline Amikacin & $36(100 \%)$ & $13(100 \%)$ & $23(100 \%)$ \\
\hline Tigecycline & $36(100 \%)$ & $13(100 \%)$ & $23(100 \%)$ \\
\hline Meropenem & $35(97.2 \%)$ & $13(100 \%)$ & $22(95.6 \%)$ \\
\hline Fosfomycin & $35(97.2 \%)$ & $12(92.3 \%)$ & $23(100 \%)$ \\
\hline Imipenem & $34(94.4 \%)$ & $13(100 \%)$ & $21(91.3 \%)$ \\
\hline Ertapenem & $33(91.6 \%)$ & $12(92.3 \%)$ & $21(91.3 \%)$ \\
\hline Piperacillin-tazobactam & $32(88.9 \%)$ & $12(92.3 \%)$ & $20(86.9 \%)$ \\
\hline Nitrofurantoin & $31(86.1 \%)$ & $11(84.6 \%)$ & $20(86.9 \%)$ \\
\hline Gentamicin & $29(80.5 \%)$ & $8(61.5 \%)$ & $21(91.3 \%)$ \\
\hline Tobramycin & $26(72.2 \%)$ & $5(38.4 \%)$ & $21(91.3 \%)$ \\
\hline Norfloxacin & $21(58.3 \%)$ & $3(23.1 \%)$ & $18(78.2 \%)$ \\
\hline Ciprofloxacin & $19(52.8 \%)$ & $2(15.3 \%)$ & $17(73.9 \%)$ \\
\hline Cefepime & $19(52.8 \%)$ & $0(0 \%)$ & $19(82.6 \%)$ \\
\hline Cefazolin & $18(50 \%)$ & $0(0 \%)$ & $18(78.2 \%)$ \\
\hline Ceftazidime & $18(50 \%)$ & $0(0 \%)$ & $18(78.2 \%)$ \\
\hline Ceftriaxone & $18(50 \%)$ & $0(0 \%)$ & $18(78.2 \%)$ \\
\hline Aztreonam & $18(50 \%)$ & $0(0 \%)$ & $18(78.2 \%)$ \\
\hline Trimethoprim-sulfamethoxazole & $18(50 \%)$ & $2(15.3 \%)$ & $16(69.5 \%)$ \\
\hline Amoxycillin-clavulinic acid & $17(47.2 \%)$ & $0(0 \%)$ & $17(73.9 \%)$ \\
\hline Ampicillin & $10(27.8 \%)$ & $0(0 \%)$ & $10(43.4 \%)$ \\
\hline
\end{tabular}

To evaluate Multidrug Resistance (MDR), sensitivity to each drug group was evaluated and resistance to one or more antibiotic in a group was considered as resistance to the group. It was observed that resistance was highest in case of Aminopenicillin group (72.2\%) followed by Cephalosporins, Folate Pathway Inhibitor and Monobactam (50\% each), Beta-lactam-beta-lactam Inhibitor (47.2\%), Fluoroquinilones (44.4\%) and Aminoglycosides $(27.8 \%)$. In ESBL producers highest resistance was showed by Aminopenicillin, Cephalosporins, Monobactam and Beta-lactam-betalactam Inhibitor group (100\% each), followed by Folate Pathway Inhibitor (84.6\%), Fluoroquinilones (76.9\%) and Aminoglycosides (61.5\%). In case of ESBL nonproducers highest resistance was observed in Aminopenicillin group $(56.5 \%)$ followed by Folate Pathway Inhibitor (30.4\%) and Fluoroquinilones (26.0\%) (Table 4). 
Table 4: Percentage of resistance of Escherichia coli against various groups of antibiotics.

\begin{tabular}{|c|c|c|c|c|c|}
\hline $\begin{array}{l}\text { Groups of } \\
\text { antibiotics }\end{array}$ & $\begin{array}{l}\text { Class of } \\
\text { antibiotic }\end{array}$ & $\begin{array}{l}\text { Antibiotic } \\
\text { used }\end{array}$ & $\begin{array}{l}\text { Total resistant } \\
\text { isolates } \\
(\mathrm{n}=36) \text { No. }(\%)\end{array}$ & $\begin{array}{l}\text { Resistant isolates in } \\
\text { ESBL producer } \\
(n=13) \text { No. }(\%)\end{array}$ & $\begin{array}{l}\text { Resistant isolates in } \\
\text { ESBL non- producer } \\
(\mathrm{n}=\mathbf{2 3}) \text { No. }(\%)\end{array}$ \\
\hline Group 1 & Aminoglycoside & $\begin{array}{l}\text { Amikacin, } \\
\text { Gentamicin } \\
\text { Tobramycin }\end{array}$ & $10(27.8 \%)$ & $8(61.5 \%)$ & $2(8.7 \%)$ \\
\hline Group 2 & Carbepenem & $\begin{array}{l}\text { Imipenem } \\
\text { Meropenem } \\
\text { Ertapenem }\end{array}$ & $3(8.3 \%)$ & $1(7.7 \%)$ & $2(8.7 \%)$ \\
\hline Group 3 & Fluoroquinolone & $\begin{array}{l}\text { Ciprofloxacin } \\
\text { Norfloxacin }\end{array}$ & $16(44.4 \%)$ & $10(76.9 \%)$ & $6(26.0 \%)$ \\
\hline \multirow{3}{*}{ Group 4} & $\begin{array}{l}\text { Cephalosporin- - } \\
1^{\text {st }} \text { Generation }\end{array}$ & Cefazolin & \multirow{3}{*}{$18(50 \%)$} & \multirow{3}{*}{$13(100 \%)$} & \multirow{3}{*}{$5(21.7 \%)$} \\
\hline & $3^{\text {rd }}$ Generation & $\begin{array}{l}\text { Ceftriaxone } \\
\text { Ceftazidime }\end{array}$ & & & \\
\hline & $4^{\text {th }}$ Generation & Cefepime & & & \\
\hline Group 5 & $\begin{array}{l}\text { Folate pathway } \\
\text { inhibitor }\end{array}$ & $\begin{array}{l}\text { Trimethoprim- } \\
\text { sulfamethoxaz } \\
\text { ole }\end{array}$ & $18(50 \%)$ & $11(84.6 \%)$ & $7(30.4 \%)$ \\
\hline Group 6 & Furadantin & Nitrofurantoin & $2(5.6 \%)$ & $1(7.7 \%)$ & $1(4.3 \%)$ \\
\hline Group 7 & $\begin{array}{l}\text { Beta-lactam- } \\
\text { beta-lactam } \\
\text { Inhibitor }\end{array}$ & $\begin{array}{l}\text { Amoxycillin- } \\
\text { clavulinic acid } \\
\text { Piperacillin- } \\
\text { tazobactam }\end{array}$ & $17(47.2 \%)$ & $13(100 \%)$ & $4(17.4 \%)$ \\
\hline Group 8 & Monobactam & Aztreonam & $18(50 \%)$ & $13(100 \%)$ & $5(21.7 \%)$ \\
\hline Group 9 & Aminopenicillin & Ampicillin & $\begin{array}{l}26 \\
(72.2 \%)\end{array}$ & $\begin{array}{l}13 \\
(100 \%)\end{array}$ & $13(56.5 \%)$ \\
\hline Group 10 & $\begin{array}{l}\text { Phosphonic acid } \\
\text { derivative }\end{array}$ & Fosfomycin & $1(2.8 \%)$ & $1(7.7 \%)$ & $0(0 \%)$ \\
\hline Group 11 & Tetracycline & Tigecycline & $0(0 \%)$ & $0(0 \%)$ & $0(0 \%)$ \\
\hline
\end{tabular}

Table 5: Percentage of multidrug resistant (MDR) and all drug group sensitive isolates of Escherichia coli.

\begin{tabular}{|c|c|c|c|}
\hline $\begin{array}{l}\text { MDR } \\
\text { (Multi-drug Resistant) } \\
\text { Antibiotics }\end{array}$ & $\begin{array}{l}\text { Total resistant isolates } \\
(n=36) \text { No. }(\%)\end{array}$ & $\begin{array}{l}\text { Resistant isolates in } \\
\text { ESBL producer }(n=13) \\
\text { No. }(\%)\end{array}$ & $\begin{array}{l}\text { Resistant isolates in } \\
\text { ESBL non- producer } \\
(\mathbf{n}=\mathbf{2 3}) \text { No. }(\%)\end{array}$ \\
\hline Resistance to 3 drug groups & $0(0 \%)$ & $0(0 \%)$ & $0(0 \%)$ \\
\hline Resistance to 4 drug groups & $0(0 \%)$ & $0(0 \%)$ & $0(0 \%)$ \\
\hline Resistance to 5 drug groups & $7(19.4 \%)$ & $4(30.8 \%)$ & $3(13.0 \%)$ \\
\hline Resistance to 6 drug groups & $2(5.6 \%)$ & $1(7.7 \%)$ & $1(4.3 \%)$ \\
\hline Resistance to 7 drug groups & $7(19.4 \%)$ & $7(53.8 \%)$ & $0(0 \%)$ \\
\hline Resistance to 8 drug groups & $1(2.8 \%)$ & $0(0 \%)$ & $1(4.3 \%)$ \\
\hline Resistance to $\geq 9$ drug groups & $1(2.8 \%)$ & $1(7.7 \%)$ & $0(0 \%)$ \\
\hline Total MDR & $18(50 \%)$ & $13(100 \%)$ & $5(21.7 \%)$ \\
\hline All group sensitive antibiotics & $\begin{array}{l}\text { Total } \\
\text { Sensitive isolates }(n=36) \\
\text { No. }(\%)\end{array}$ & $\begin{array}{l}\text { Sensitive isolates in } \\
\text { ESBL producer }(n=13) \\
\text { No. }(\%)\end{array}$ & $\begin{array}{l}\text { Sensitive isolates in } \\
\text { ESBL non- producer } \\
(\mathrm{n}=23) \text { No. }(\%)\end{array}$ \\
\hline Sensitive to all 11 drug groups & $8(22.2 \%)$ & $0(0 \%)$ & $8(34.8 \%)$ \\
\hline
\end{tabular}

Total number of multidrug resistant (MDR) Escherichia coli isolates were $18(50 \%)$. All the isolates of ESBL producers are MDR (100\%) and $21.7 \%$ of ESBL nonproducers are MDR. All the MDR isolates were resistant to 5 or more groups of drugs. The highest percentage of MDR are resistant to 5 and 7 drug groups (19.4\% each).
Whereas ESBL isolates also showed high resistance to these two drug groups (30.8\% and $53.8 \%$ respectively).

Resistance to 8 and $\geq 9$ drug groups are less (2.8\% each). But there were 8 isolates $(22.2 \%)$ which were sensitive to all the 11 drug groups and all of them were ESBL non- 
producers, which again constitutes $34.8 \%$ of all the ESBL non-producers (Table 5).

\section{DISCUSSION}

Escherichia coli, an Enterobacteriaceae, is a normal intestinal flora and is the most commonly reported cause of UTI, being a common fecal contaminant. Due to short length of urethra in females and closeness of female anus and vagina to the urethra, the organism gets inoculated into the urethra during process of anal cleaning after defecation or during sexual intercourse.

Washing of genitals from back to front is more likely to lead to spread of anal or vaginal flora into urethra. Health education on the direction of washing and advice to micturate shortly after sexual activity can reduce the chances of getting UTI. If asymptomatic bacteriuria (ASB) is left undiagnosed, there is risk of developing acute pyelonephritis in pregnant women which is associated with preterm labour. Early diagnosis and treatment of ASB can reduce the incidence of pyelonephritis and prevent preterm labour. ${ }^{3,4}$

The present study revealed Escherichia coli as the predominant isolate from urine samples of female patients, which well correlates with many studies. ${ }^{3-5,8-12}$ The age group wise distribution showed that Escherichia coli isolates were mostly prevalent in adult age group (21-40 years), which also correlates well with the studies conducted by Patnaik M et al, Oli A N et al and Arora G et al. . $^{2,13}$

The antibiotic sensitivity pattern of Escherichia coli in this study showed very good sensitivity towards Amikacin, Tigecycline, Meropenem, Fosfomycin, Imipenem, Ertapenem, Piperacillin-tazobactam, Nitrofurantoin, Gentamicin and Tobramycin, whereas showed moderate sensitivity towards Norfloxacin, Ciprofloxacin, Cefepime, Cefazolin, Ceftazidime, Ceftriaxone, Aztreonam and Trimethoprimsulfamethoxazole and showed low sensitivity towards Amoxycillin-clavulinic acid and Ampicillin.

Similar pattern of antibiotic sensitivity was also shown by Elzayat MAA et al, Shaifali I et al, Gupta K et al and Kumari A et al. ${ }^{3,8,9,14}$ In case of ESBL producers, the overall sensitivity decreases except Amikacin, Tigecycline, Carbapenems and Piperacillin-tazobactam.

In case of non- $\beta$-lactam antibiotics the sensitivity decreases in ESBL producer strains which may be due to transfer of resistance genes for these non- $\beta$-lactam antibiotics along with ESBL resistance marker. Such type of coexistence of ESBL producer and other non- $\beta$-lactam antibiotic resistance marker was reported by Babypadmini S et al, as ESBLs are encoded by plasmids, which carry resistance genes for other antibiotics also. ${ }^{6}$ The evaluation of multidrug resistance pattern showed that $50 \%$ of all the isolates were MDR and most of the isolates were resistant to more than 5 drug groups while only $22.2 \%$ of isolates were sensitive to all the drug groups. All the ESBL producer isolates were MDR. Similar pattern of multidrug resistance was also showed by Mukherjee $M$ et al. ${ }^{15}$ The correlation of ESBL producer and MDR in this study closely resembles the study conducted by Raijini CY et al. ${ }^{7}$

The first line of antibiotic for treatment of uncomplicated urinary tract infection in females is Trimethoprimsulfamethoxazole while in second line it is fluoroquinolones. ${ }^{16}$ There are reports of increasing resistance of Ciprofloxacin and Trimethoprimsulfamethoxazole over the years due to overuse of these antibiotics and treatment failure with Trimethoprimsulfamethoxazole in areas with high prevalence of resistance with this antibiotic has been reported. ${ }^{17,18}$ Study conducted by Gobernado $M$ et al found Fosfomycin as the best drug against Escherichia coli in uncomplicated cystitis. ${ }^{19}$

Infectious Disease Society of America (IDSA) (2010 update) recommends Nitrofurantoin as the first choice followed by Trimethoprim-sulfamethoxazole, Fosfomycin etc. ${ }^{20}$ Nitrofurantoin has shown very low level of resistance but may cause birth defects and should be cautiously used. ${ }^{21}$ Patients infected with ESBL producer Escherichia coli strains, cannot be treated with $\beta$-lactam antibiotics and monobactams. ${ }^{6}$

As in our study high sensitivity was shown by Amikacin, Nitrofurantoin and Fosfomycin, these antibiotics can be used as alternatives for emperical treatment of such patients at low cost, as Nitrofurantoin and Fosfomycin are available in oral form, provided Nitrofurantoin is cautiously used in pregnant women. Also measures to be taken to preserve higher end antibiotics like carbapenems and Piperacillin-tazobactam and should be used only in non-responsive cases.

\section{CONCLUSION}

In this study Escherichia coli was the predominant uropathogen isolated from female patients and mostly resistant to commonly prescribed drugs and clinicians are left with very few alternative drugs.

The antimicrobial resistance pattern showed that fluoroquinolones or cephalosporins may not be appropriate first line agents in empirical treatment of urinary tract infections. Instead Amikacin, Nitrofurantoin and Fosfomycin can be used as first line drug, out of which Amikacin is available in injectable form and Nitrofurantoin and Fosfomycin available as oral antibiotic.

\author{
Funding: No funding sources \\ Conflict of interest: None declared \\ Ethical approval: The study was approved by the \\ Institutional Ethics Committee
}




\section{REFERENCES}

1. Karlowsky JA, Kelly LJ, Thornsberry C, Jones ME, Sahm DF. Trends in Antimicrobial Resistance among Urinary Tract Infection Isolates of Escherichia coli from Female Outpatients in the United States. Antimicrob Agents Chemother 2002; 46(8):2540-45.

2. Patnaik M, Panigrahi K, Das B, Pathi B, Poddar N, Lenka PR et al. Prevalence, risk factors and causative organisms of asymptomatic bacteriuria in pregnancy. Int J Adv Med. 2017;4(5):1348-54.

3. Abdel-Aziz Elzayat M, Barnett-Vanes A, Dabour MFE, Cheng F. Prevalence of undiagnosed asymptomatic bacteriuria and associated risk factorsduring pregnancy: a cross-sectional study at two tertiary centres in Cairo, Egypt. BMJ Open 2017;7(3):e013198.

4. Oli AN, Akabueze VB, Ezeudu CE, Eleje GU, Ejiofor OS, Ezebialu IU et al. Bacteriology and Antibiogram of Urinary Tract Infection Among Female Patients in a Tertiary Health Facility in South Eastern Nigeria. The Open Microbiol J 2017;11:292-300.

5. Paari P, Sindhuja TP, Dhinakaran S, Paul CMP. A cross-sectional study on asymptomatic bacteriuria among antenatal women attending an urban tertiary health care centre in Southern India. Int $\mathrm{J}$ Reprod Contracept Obstet Gynecol. 2017;6(10):4522-25.

6. Babypadmini S, Appalaraju B. Extended Spectrum $\beta$ Lactamases in Urinary Isolates of Escherichia coli and Klebsiella pneumoniae- Prevalence and Susceptibility Pattern in a Tertiary Care Hospital. Indian $\mathrm{J}$ Med Microbiol. 2004;22(3):172-4.

7. Ranjini CY, Kasukurthi LR, Madhumati B, Rajendran R. Prevalence of multidrug resistance and extended spectrum beta-lactamases among uropathogenic Escherichia coli isolates in a tertiary care hospital in South India: An alarming trend. Community Acquir Infect. 2015;2(1):19-24.

8. Shaifali I, Gupta U, Mahmood SE, Ahmed J. Antibiotic Susceptibility Patterns of Urinary Pathogens in Female Outpatients. N Am J Med Sci. 2012; 4(4):163-9.

9. Gupta K, Sahm DF, Mayfield D, Stamm WE. Antimicrobial Resistance Among Uropathogens that Cause Community-Acquired Urinary Tract Infections in Women: A Nationwide Analysis. Clin Infect Dis. 2001;33(1):89-94.

10. McCarty JM, Richard G, Huck W, Tucker RM, Tosiello $\mathrm{RL}$, Shan $\mathrm{M}$ et al. A randomized trial of short-course ciprofloxacin, ofloxacin

or trimethoprim/sulfamethoxazole for the treatment of acute urinary tract infection in women. Am J Med 1999;106(3):292-9.

11. Manjula NG, Math GC, Patil SA, Gaddad SM, Shivannavar CT. Incidence of Urinary Tract Infections and Its Aetiological Agents among Pregnant Women in Karnataka Region. Advances Microbiol. 2013;3(6):4738.

12. Gessese YA, Damessa DL, Amare MM, Bahta YH, Shifera AD, Tasew FS et al. Urinary pathogenic bacterial profile, antibiogram of isolates and associated risk factors among pregnant women in Ambo town, Central Ethiopia: a cross-sectional study. Antimicrob Resist Infect Control. 2017; 6(1):132.

13. Arora G, Kaur P, Agrawal D. Urinary tract infection in women of rural population of Haryana: a rising problem. Int J Reprod Contracept Obstet Gynecol. 2016;5(12):4470-74.

14. Kumari A, Kumar S, Kumar S. Observation on Prevalence and Mechanism of Multi Drug Resistant Escherichia coli Causing Uncomplicated Urinary Tract Infection in Female. International Journal of Contemporary Medical Research 2016;3(10):2895-7.

15. Mukherjee M, Koley S, Mukherjee SK, Basu S, Ghosh B, Chakraborty S. Phylogenetic background of E.coli isolated from asymptomatic pregnant women from Kolkata, India. J Infect Dev Ctries 2015;9(7):720-4.

16. Hotchandani R, Aggarwal KK. Urinary Tract Infections in Women. Indian J Clinical Practice. 2012;23(4);18792.

17. Sanchez GV, Babiker A, Master RN, Luu T, Mathur A, Bordon J. Antibiotic Resistance among Urinary Isolates from Female Outpatients in the United States in 2003 and 2012. Antimicrob Agents Chemother 2016;60(5):2680-3.

18. Raz R, Chazan B, Kennes Y, Colodner R, Rottensterich E, Dan $M$ et al. Empiric Use of TrimethoprimSulfamethoxazole (TMP-SMX) in the Treatment of Women with Uncomplicated Urinary Tract Infections, in a Geographical Area with a High Prevalence of TMP-SMX-Resistant Uropathogens. Clin Infect Dis. 2002;34(9):1165-69.

19. Gobernado M, Valdes L, Alos JI, Gracia-Rey C, Dal-Re R, Garcia-de-Lomas J et al. Antimicrobial susceptibility of clinical Escherichia coli isolates from uncomplicated cystitis in women over a 1-year period in Spain. Rev Esp Quimioter 2007;20(1):68-76.

20. Gupta K, Hooton TM, Naber KG, Wullt B, Colgan R, Miller LG et al. International Clinical Practice Guidelines for the Treatment of Acute Uncomplicated Cystitis and Pyelonephritis in Women: A 2010 Update by the Infectious Diseases Society of America and the European Society for Microbiology and Infectious Diseases. Clin Infect Dis. 2011;2(5):103-20.

21. Das A, Banerjee T. Prevalence of Urinary Tract Infections and Susceptibility Pattern of Uropathogens in Women of Reproductive age Group from North India. J Advances Med. 2015;4(1-2):5-9.

Cite this article as: Das B, Mittal N, Goswami R, Adhana D, Rathore N. Prevalence of multidrug resistance (MDR) and extended spectrum betalactamases (ESBLs) among uropathogenic Escherichia coli isolates from female patients in a tertiary care hospital in North India. Int J Reprod Contracept Obstet Gynecol 2018;7:5031-6. 